\title{
Contribution of Doppler Echocardiography to the Evaluation of Systolic and Diastolic Function of Obese Women versus a Control Group
}

\author{
Nathan Herszkowicz, Alfonso Barbato, Waldir Salvi, Daniel Pinheiro, Denise Pantaleão, \\ Alfredo Halpern, Giovani G. Cerri \\ São Paulo, SP - Brazil
}

\begin{abstract}
Objective - To study by doppler echocardiography the cardiac systolic and diastolic functions of health, uncomplicated obese subjects.

Methods - Fifty-nine obese women with an average body mass index (BMI) of $35 \mathrm{~kg} / \mathrm{m}^{2}$ were evaluated and compared with 19 subjects with an average BMI of $23 \mathrm{~kg} /$ $m^{2}$ (control group).
\end{abstract}

Results - In the obese group, a clear tendency was observed toward higher systolic pressure, increased wall thickness and, consequently, myocardial mass, elevation on the circumference stress of the left ventricular wall, and an indisputable presence of diastolic abnormalities. Filling abnormalities were observed with impaired relaxation, with prolonged isovolumic relaxation time (IVRT) and augmented atrium contribution representing early indexes of cardiac dysfunction when systolic performance is still normal.

Conclusion - Obesity is generally a chronic condition, and doppler echocardiography can be used as a noninvasive instrument for early evaluation of left ventricular diastolic indexes.

Key words: obesity, echocardiography, cardiopathy

InRad - Institute of Radiology, and Group of Obesity and Metabolic Diseases of the Endocrinology Service - Hospital das Clínicas - University of São Paulo. Mailing address: Alfonso Barbato - Rua Abílio Soares, 233/63 - São Paulo, SP 04005-000 - Brazil - E-mail: abto@uol.com.br
"Sudden death is more frequent in those who are naturally obese than in those who are lean"-Hypocrites, aphorism 44 (Cos Island, $460 \mathrm{BC}$ ).

The first modern postulation about the interrelationship between obesity, heart disease, and sudden death was made by Corvisat ${ }^{1}$ in 1806 . He described the presence of adipose tissue around the heart and suggested that it could be compressed (restrictive cardiopathy), leading to sudden death.

In 1819 , the anatomopathologist Laennec ${ }^{2}$ coined the expression "adipose heart" to differentiate between the deposition of adipose tissue on the cardiac surface and the greasy degeneration of myocardial fibers that results in an organ of pallid appearance, "similar to dead leaves".

Only in 1933 did Smith and Willius ${ }^{3}$ publish a paper correlating body weight with cardiac mass, as well as the association between severity of obesity and congestive heart failure.

The first echocardiographic study in patients with morbid obesity was performed by Alexander at al. ${ }^{4}$ in 1978 , when 2 distinct functional patterns among their patients were described as follows: Group I: patients with normal ejection fraction (EF), volume/mass (V/M) ratio and, consequently, normal parietal stress (Str); Group II: patients with augmented final diastolic volume, increased V/M ratio, increased Str and reduced EF.

Finally, in 1982 Cueto Garcia et al. ${ }^{5}$ performed an echocardiographic study in a group of morbidly obese patients and described an important increase in left ventricular mass with dilated chambers, probably secondary to eccentric hypertrophy, which he called "inadequate".

The purpose of the present study was to evaluate uncomplicated obese patients, and analyze left ventricular systolic and diastolic functions by Doppler echocardiography, before administering a drug for weight loss. 


\section{Methods}

Fifty-nine women, average age $39.56 \pm 11.30$ years and body mass index (BMI) of $35 \pm 6 \mathrm{~kg} / \mathrm{m}^{2}$, were selected. For the present study, we considered normal weight to be $\mathrm{BMI}=20$ $25 \mathrm{~kg} / \mathrm{m}^{2}$, overweight to be BMI $=25-30 \mathrm{~kg} / \mathrm{m}^{2}$, obese to be $\mathrm{BMI}=30-40 \mathrm{~kg} / \mathrm{m}^{2}$, and morbid obesity to be $\mathrm{BMI}>40 \mathrm{~kg} /$ $\mathrm{m}^{2}$. Patients with systemic arterial hypertension, diabetes, cardiopathy, and kidney, brain, and lung complications were excluded. The remaining patients were considered "healthy" or "normal" obese. They were compared with 19 healthy women, with a mean age \pm SD of $32.16 \pm 9.39$ years, and $\mathrm{BMI} \pm \mathrm{SD}$ of $23 \pm 4 \mathrm{~kg} / \mathrm{m}^{2}$.

Anthropometric and clinical parameters included age $(A)$, weight $(\mathrm{W})$, height $(\mathrm{H})$, body surface $(\mathrm{BS})$, heart rate (HR), and systolic arterial pressure (SP). Both groups underwent Doppler echocardiography with color flow mapping, according to the technique established and proposed by the American Society of Echocardiography (ASE).

A System Five $^{\circledR}$ - Ving Med (General Electric) device was used in the present study, which has the capability of generating and receiving second harmonic echos and has a trigger synchronized with the ECG.

The echocardiographic variables considered were the following: Direct linear measurements - aorta (Ao), left atrium(LA), left ventricle (LV), left ventricular diastolic (Dd), and systolic $(\mathrm{Sd})$ diameters, diastolic $(\mathrm{Sd})$ and systolic $(\mathrm{Ss})$ thickness of the septum and posterior wall (Pd and Ps, respectively), amplitudes of mitral $\mathrm{E}$ and $\mathrm{A}$ waves (Mve and Mva, respectively).

Indirectly calculated measurements - diastolic (Dv) and systolic (Sv) volumes, left ventricle mass (M) and mass index (MI), the ratios Dv/M, Mve/Mva, systolic wall stress (Str), percentage of LV systolic shortening $(\Delta \mathrm{d} \%)$, percentage of systolic septum $(\Delta \mathrm{S} \%)$ and $\mathrm{LV}$ posterior wall $(\mathrm{DP} \%)$ thickness, and left ventricular ejection fraction (EF).
Direct measurements of time intervals-isovolumic relaxation time (IVRT), mitral flow acceleration and deceleration time ( Ta and Td, respectively ).

Statistical analysis - The statistical analysis was performed based on the calculations of means \pm standard deviations (SD), confidence intervals (CI), and by the unpaired Student'st test. The level of significance was set at $\mathrm{p}<0.05$.

\section{Results}

The large number of cases in each group, making up to a total of 78 women, together with the massive number of variables considered, resulted in extremely large tables. We, therefore, opted to only present the mean $\pm \mathrm{SD}$, the confidence intervals (CI) and the statistical comparisons of the most significant and relevant parameters for the comprehension of the present study (Tables I to V).

\section{Discussion}

The pathophysiology of the heart alterations observed in obese subjects is generally unclear. It is known, however, that in the obese patient a significant augmentation of circulating plasma volume occurs, and, consequently, increments in the blood volume, which leads to an important increase of the peripheral vascular bed ${ }^{6}$. To compensate for the increase in blood volume and in the capillary net, the cardiac debt is elevated proportionally to the excessive weight in relation to the ideal weight. Similarly, a significant increase occurs in oxygen consumption by the active metabolism of the adipose tissue, which is also proportional to the magnitude of the excess weight, such that most of the heart debt of the obese subject is destined to supply the fat tissue cells.

These subjects also showed a clear elevation of LV filling pressure as a consequence of a less compliant

\begin{tabular}{|c|c|c|c|c|}
\hline & A (years)* & W (kg)* & $\operatorname{BSA}\left(\mathrm{m}^{2}\right)^{*}$ & BMI $\left(\mathrm{kg} / \mathrm{m}^{2}\right)^{*}$ \\
\hline $\begin{array}{l}\mathrm{Ob}(\mathrm{n}=59) \\
{[\mathrm{IC}, 95 \%]}\end{array}$ & $\begin{array}{c}39.56 \pm 11.30 \\
{[36.68 ; 42.44]}\end{array}$ & $\begin{array}{c}88.66 \pm 14.91 \\
{[84.86 ; 92.47]}\end{array}$ & $\begin{array}{c}1.90 \pm 0.17 \\
{[1.85 ; 1.94]}\end{array}$ & $\begin{array}{c}35 \pm 6 \\
{[34 ; 37]}\end{array}$ \\
\hline $\begin{array}{l}\mathrm{Nl}(\mathrm{n}=19) \\
{[\mathrm{IC}, 95 \%]}\end{array}$ & $\begin{array}{c}32.16 \pm 9.39 \\
{[27.94 ; 36.38]}\end{array}$ & $\begin{array}{c}61.32 \pm 11.63 \\
{[56.09 ; 66.55]}\end{array}$ & $\begin{array}{c}1.65 \pm 0.16 \\
{[1.57 ; 1.72]}\end{array}$ & $\begin{array}{c}23 \pm 4 \\
{[22 ; 25]}\end{array}$ \\
\hline
\end{tabular}

\begin{tabular}{|c|c|c|c|c|c|}
\hline & $\mathrm{Ao}(\mathrm{cm})^{*}$ & $\mathrm{SP}(\mathrm{mmHg})^{*}$ & $\mathrm{LA}(\mathrm{cm})^{*}$ & $\mathrm{Sd}(\mathrm{cm})^{*}$ & $\mathrm{Pd}(\mathrm{cm})^{*}$ \\
\hline $\begin{array}{l}\mathrm{Ob}(\mathrm{n}=59) \\
{[\mathrm{IC}, 95 \%]}\end{array}$ & $\begin{array}{c}29.46 \pm 3.13 \\
{[28.66 ; 30.26]}\end{array}$ & $\begin{array}{c}118.11 \pm 15.70 \\
{[114.13 ; 122.14]}\end{array}$ & $\begin{array}{c}35.76 \pm 3.49 \\
{[34.87 ; 36.65]}\end{array}$ & $\begin{array}{c}9.24 \pm 1.26 \\
{[8.92 ; 9.56]}\end{array}$ & $\begin{array}{l}8.73 \pm 0.89 \\
{[8.50 ; 8.96]}\end{array}$ \\
\hline $\begin{array}{l}\mathrm{Nl}(\mathrm{n}=19) \\
{[\mathrm{IC}, 95 \%]}\end{array}$ & $\begin{array}{c}27.42 \pm 2.85 \\
{[26.14 ; 28.70]}\end{array}$ & $\begin{array}{c}104.70 \pm 17.43 \\
{[96.90 ; 112.57]}\end{array}$ & $\begin{array}{c}32.11 \pm 3.86 \\
{[30.37 ; 33.84]}\end{array}$ & $\begin{array}{c}7.68 \pm 1.00 \\
{[7.23 ; 8.13]}\end{array}$ & $\begin{array}{c}6.37 \pm 1.61 \\
{[5.64 ; 7.09]}\end{array}$ \\
\hline
\end{tabular}




\begin{tabular}{|c|c|c|c|c|}
\hline & $\operatorname{Dd}(\mathrm{cm})^{*}$ & $\operatorname{Vd}\left(\mathrm{cm}^{3}\right)^{*}$ & $\mathrm{Dv} / \mathrm{M}(\mathrm{ml} / \mathrm{g})^{*}$ & $\operatorname{IM}\left(\mathrm{g} / \mathrm{m}^{2}\right)^{*}$ \\
\hline $\begin{array}{l}\mathrm{Ob}(\mathrm{n}=59) \\
{[\mathrm{CI}, 95 \%]}\end{array}$ & $\begin{array}{c}49.22 \pm 3.42 \\
{[48.35 ; 50.09]}\end{array}$ & $\begin{array}{c}120.9 \pm 23.77 \\
{[114.84 ; 126.97]}\end{array}$ & $\begin{array}{c}0.79 \pm 0.13 \\
{[0.76 ; 0.83]}\end{array}$ & $\begin{array}{c}81.70 \pm 15.28 \\
{[77.80 ; 85.60]}\end{array}$ \\
\hline $\begin{array}{l}\text { Nl }(\mathrm{n}=19) \\
{[\mathrm{CI}, 95 \%]}\end{array}$ & $\begin{array}{c}47.37 \pm 3.96 \\
{[45.59 ; 49.15]}\end{array}$ & $\begin{array}{c}108.3 \pm 25.66 \\
{[96.82 ; 119.90]}\end{array}$ & $\begin{array}{c}1.05 \pm 0.24 \\
{[0.94 ; 1.16]}\end{array}$ & $\begin{array}{c}64.55 \pm 17.26 \\
{[56.79 ; 72.31]}\end{array}$ \\
\hline
\end{tabular}

\begin{tabular}{|lcccc|}
\hline \multicolumn{5}{|c|}{ Table IV - Mass and global echocardiographic systolic indexes of obese vs. normal subjects } \\
\hline & $\mathrm{M}(\mathrm{g})^{*}$ & $\mathrm{Str}\left(\mathrm{g} / \mathrm{cm}^{2}\right)^{*}$ & $\Delta \mathrm{d} \% \%^{*}$ & FE* \\
\hline $\mathrm{Ob}(\mathrm{n}=59)$ & $154.3 \pm 29.80$ & $132.28 \pm 23.42$ & $37.38 \pm 3.19$ & $0.75 \pm 0.04$ \\
{$[\mathrm{IC}, 95 \%]$} & {$[146.77 ; 161.97]$} & {$[126.05 ; 138.51]$} & {$[36.56 ; 38.19]$} & {$[0.74 ; 0.76]$} \\
\hline $\mathrm{Nl}(\mathrm{n}=19)$ & $106.6 \pm 31.98$ & $110.16 \pm 29.19$ & $41.42 \pm 5.18$ & $0.79 \pm 0.05$ \\
{$[\mathrm{IC}, 95 \%]$} & {$[92.23 ; 120.99]$} & {$[97.03 ; 123.28]$} & {$[39.10 ; 43.75]$} & {$[0.77 ; 0.82]$} \\
\hline$*$ Significant at $\mathrm{p}<0.05 ;$ M- left ventricular mass; Str- systolic wall stress; $\Delta \mathrm{d} \%$ - fractional shortening; FE- ejection fraction. \\
\hline
\end{tabular}

\begin{tabular}{|c|c|c|c|c|}
\hline & $\operatorname{Mve}(\mathrm{m} / \mathrm{s})^{* *}$ & $\operatorname{Mva}(\mathrm{m} / \mathrm{s})^{*}$ & Mve/Mva* & $\operatorname{IVRT}(\mathrm{ms})^{*}$ \\
\hline $\begin{array}{l}\text { Ob }(n=59) \\
{[\mathrm{IC}, 95 \%]}\end{array}$ & $\begin{array}{c}0.86 \pm 0.17 \\
{[0.81 ; 0.90]}\end{array}$ & $\begin{array}{c}0.76 \pm 0.18 \\
{[0.71 ; 0.80]}\end{array}$ & $\begin{array}{c}1.18 \pm 0.30 \\
{[1.10 ; 1.26]}\end{array}$ & $\begin{array}{c}101.07 \pm 20.47 \\
{[95.84 ; 106.29]}\end{array}$ \\
\hline $\begin{array}{l}\mathrm{Nl}(\mathrm{n}=19) \\
{[\mathrm{IC}, 95 \%]}\end{array}$ & $\begin{array}{c}0.92 \pm 0.17 \\
{[0.85 ; 1.00]}\end{array}$ & $\begin{array}{c}0.60 \pm 0.16 \\
{[0.53 ; 0.68]}\end{array}$ & $\begin{array}{c}1.62 \pm 0.46 \\
{[1.41 ; 1.83]}\end{array}$ & $\begin{array}{c}88.74 \pm 14.25 \\
{[82.33 ; 95.14]}\end{array}$ \\
\hline
\end{tabular}

chamber. This hemodynamic pattern has been shown to be reversible with a marked weight reduction ${ }^{7-8}$. Thus, in cases of remarkable obesity a true hypervolemic syndrome associated with a hyperkinetic state, with high-energy expenditure is observed. It is important to emphasize that the intensity of the observed alterations is proportional to the length of installation or living with this hemodynamic situation. Because no cases of morbid obesity existed and this was a homogenous and well-selected sample, from which were excluded the main factors that might lead to cardiovascular alterations, we expected anatomically and functionally normal hearts.

It is noteworthy that in our results the average weight of the obese women was $44 \%$ greater than that of the control group, and the difference in BMI between the groups was $45 \%$, indicating that these groups were composed of truly distinct populations, despite the fact that they were made of, theoretically, normal subjects from the cardiovascular point of view.

Maybe one of the most important observations in the present study was the significantly higher values of thickness of the septum and of the LV posterior wall, and consequently, the ventricular mass in the obese women, although both groups had normal cavity diameters. Therefore, the ratio between $\mathrm{Vd} / \mathrm{M}$, which defines hypertrophy, was significantly smaller in the obese women $(0.79 \mathrm{vs} 1.05 ; \mathrm{p}<0.05)$. It is important to emphasize that the values of this relationship $\mathrm{Vd} / \mathrm{M}$ continue within normal limits, being considered hypertrophic in patients with values below $0.5 \mathrm{~mL} / \mathrm{g}$ using the truncated ellipsoid (2-dimensional) model, in which the normal value is $0.80 \pm 0,15 \mathrm{~mL} / \mathrm{g}^{9}$.

The hemodynamic factors per se would not be sufficient to explain the increase in cardiac mass in normotensive, nondiabetic obese patients. Sasson et al. ${ }^{10}$ attributed the hypertrophy to the insulin resistance often observed in these patients (perhaps due to a genetic inheritance), as a possible cause of hypertrophy extrinsic to the cardiovascular system (there would be an increased activity of the insulin-like growth factor).

Several studies have confirmed the significant increase of LV diameters, in addition to wall thickness and ventricular mass, proportional to the magnitude and duration of the weight gain, especially in morbidly obese subjects. In fact, Alpert et al. ${ }^{11}$ studying 62 normotensive morbidly obese patients (at least twice the ideal weight) found an increase in wall thickness in $56 \%$ and diastolic diameter in $39 \%$ of the sample, resulting in a $64 \%$ increase in cardiac mass and dilation of the left atrium in $39 \%$ of the cases. 
In our sample, the values for ventricular and atrial thickness and diameters were not altered, although all displayed statistical significance. Ventricular mass, corrected for body surface, also exhibited values within the normal range; however, it was $26.5 \%$ greater than that of nonobese women (normal values $\left.=76 \pm 18 \mathrm{~g} / \mathrm{m}^{2}\right)^{12}$. This could be explained by the lack of morbid subjects in the selection or, perhaps, by the short duration of obesity (on average, less than 4 years).

Another important finding in the healthy obese was the higher value of posterior wall circumference stress, probably secondary to the higher systolic arterial pressure levels. This finding is particularly interesting because it is known that the myocardial stress response to the component perpendicular to the wall is one of the main determinants of the development of hypertrophy and hyperplasia of muscle fibers. The meaningful alterations observed in the $\mathrm{LV}$ isovolumic relaxation time are worth emphasizing, in addition to the relative enhancement of the atrial contraction A wave, which reflects a clear incipient difficulty imposed on ventricular filling in the healthy obese. The signs of diastolic dysfunction preceding systolic impairment were also observed in the Di Devitiis et al. ${ }^{13}$ study. Concomitantly, all indexes of either global or segment systolic function were within normal limits, making believe one that the alterations found are part of a context, or better yet, of a clinical and hemodynamic situation still in a compensated state.

In conclusion, a selected population of obese women, theoretically healthy subjects, without any clinical alterations or cardiovascular complications showed a clear tendency to higher values of systolic arterial pressure, myocardial mass, LV wall circumference stress as well as a tendency to early alterations of global diastolic function, characterized by a prolonged IVRT and increased velocity of the mitral flow A wave, indicating a greater atrial contribution on the ventricular filling. Based on these findings, the authors believe that it is imperative to perform a deeper and more specific semiologic evaluation in all truly overweight patients who will undergo pharmacological or physical therapy that may affect the cardiovascular system and lead to a state of potential instability.

\section{References}

1. Corvisart JN. Essai sur les maladies et les lesions organiques du coeur et des gros vaisseux. Migneret, Paris, 1806.

2. Laennec RTH. De'l'auscultation mediate ou traite'du diagnostic des maladies des poumons et du coeur, vol. 2. Brosson and Chaudé, Paris, 1819; 295.

3. Smith HL, Willius FA. Adiposity of the heart. Ach Intern Med 1933; 52: 911-31.

4. Alexander JK, Woodard CB, Quinones MA, et al. Heart failure from obesity. In: Mancini M, Lewis B, Contaldo F. (eds). Medical Complications of Obesity. London: Academic Press, 1978: 179-87.

5. Cueto Garcia L, Laredo C, Arriaga J, et al. Echocardiographic findings in obesity. Rev Invest Clin 1982; 34: 235-41.

6. Alexander JK, Dennis EW, Smith WG, et al. Blood volume, cardiac output and distribution of systemic blood flow in extreme obesity. Cardiovasc Res Center Bull 1962; 1: 39-44.

7. Grossman E, Oren S, Messerli FH. Left ventricular filling in the systemic hypertension of obesity. Am J Cardiol 1991; 68: 57-60.
8. Alpert MA, Lambert CR, Terry BE, et al. Effect of weight loss on left ventricular diastolic filling in morbid obesity. Am J Cardiol 1995; 76: 1198-201.

9. Byrd BF, Wahr D, Wang YS, et al. Left ventricular mass and volume/mass ratio determined by two -dimensional echocardiography in normal adults. J Am Coll Cardiol 1985; 6: 1021.

10. Sasson Z, Rasooly Y, Bhesania T, et al. Insulin resistance is an important determinant of left ventricular mass in the obese. Circulation 1993; 88: 1431-6.

11. Alpert MA, Terry BE, Kelly DK. Effect of weight loss on cardiac chamber size, wall thickness nad left ventricular function in morbid obesity. Am J Cardiol 1985; 55: 783-6.

12. Devereux RB, Kutas EM, Casale PN, et al. Standardization of M-mode echocardiographic left ventricular anatomic measurements. J Am Coll Cardiol 1984; 4: 1220-30.

13. Di Devitiis O, Fazio S, Petitto M, et al. Obesity and cardiac function. Circulation 1981; 64: 477-82. 